\section{ПЕРВОЕ СВИДЕТЕЛЬСТВО НАЛИЧИЯ ОСЯЗАТЕЛЬНЫХ СЕНСОРНЫХ ЗОН У ДИЦИНОДОНТОВ (THERAPSIDA)}

\author{
М.В. Сурков \\ Научно-исследовательский институт естественных наук \\ Саратовского государственного университета, \\ кафедра геоэкологии \\ E-mail: surkovmv@info.sgu.ru
}

Впервые получено свидетельство о формировании осязательных сенсорных зон у представителя нетериодонтных терапсид Myosaurus gracilis (Dicynodontia). Система отверстий и бороздок на верхнечелюстной кости свидетельствует о наличии хорошо развитой системы кровеносных сосудов на морде Myosaurus. Сходные структуры обычно связываются с развитием сенсорных зон и вибрисс у териодонтов. Наличие тактильных сенсоров и увеличенные орбиты свидетельствуют о возможном сумеречном образе жизни Myosaurus и подтверждают опубликованные ранее идеи о насекомоядности этого животного.

The First Evidence of Tactile Sensor Zones among Dicynodonts (Therapsida)

\section{M.V. Surkov}

For the first time evedences of possible tactile sensor zones has been described in representative of non-theriodont clade of therapsids - Myosaurus gracilis (Dicynodontia). The system of foramina and grooves reflecting well developed blood network on the snout of Myosaurus is generally similar to the same descried for theriodonts and possibly represents development of sensor zones. Very large orbits and developed sensor fields on the snout of Myosaurus the most probably indicates the nocturnal mode of life and support previous ideas on omnivorous feeding.

\section{Введение}

Начиная с 30-х гг. прошлого века палеонтологи обращали внимание на концентрацию мелких отверстий и бороздок для кровеносных сосудов в районе рострального окончания морды у плотоядных синапсид: цинодонтов, тероцефалов и горгонопсов [1-5], образующих филогенетическую линию, ведущую к млекопитающим. Формирование зон с повышенным кровоснабжением и иннервацией обычно трактовалось как свидетельство наличия вибрисс или сходных образований, выполняющих ту же функцию, что и у современных млекопитающих. Развитие вибрисс также может свидетельствовать и о существовании волосяного покрова - одного из ключевых признаков теплокровности. В данной работе рассматриваются материалы, свидетельсвующие о развитие сенсорных зон на морде дицинодонта Myosaurus gracilis.

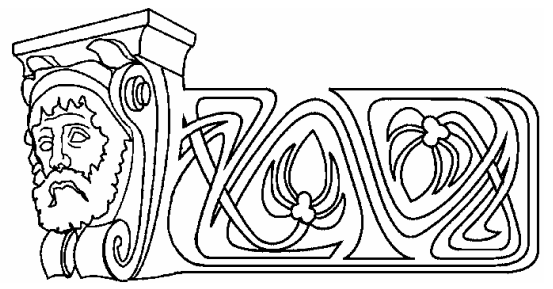

Род Myosaurus известен из раннетриасовой зоны Lystrosaurus Южной Африки и Антарктики по нескольким черепам и ассоциированным фрагментам посткраниального скелета [6-8] и рассматривается в составе семейства Emydopidae [9, 10]. Несмотря на то что детальное описание остатков Myosaurus было сделано в 1974 г. [6], дополнительное изучение оригинального материала выявило наличие инфраорбитальных отверстий и сопряженной сети кровеносных сосудов на верхнечелюстной кости, которые свидетельствуют о локальном усилении кровоснабжения и иннервации ростральных районов морды и развитии сенсорных зон.

\section{Материалы и методы}

В процессе исследований были изучены краниальные остатки:

South African Museum of Natural History (Кейптаун) AM PK 3526; SAM PK 3526a почти полные черепа Myosaurus gracilis, зона Lystrosaurus, нижний триас, Южная Африка.

Саратовский государственный университет Д-104/1-2 - череп Uralokannemeyeria vjuschkovi, Донгузская свита, средний триас; местонахождение Карагачка, Оренбургская область, Россия.

Палеонтологический институт РАН 4415/1 - почти полный череп Dicynodon sp., зона Scutosaurus karpinskii, верхняя пермь; местонахождение Ключевка, Оренбургская область, Россия.

\section{Описание}

Myosaurus gracilis - маленький дицинодонт с черепом длинной около 3,5 см. Морда слабая, ноздри расположены терминально. Орбиты очень большие, ориентированы антеро-латерально. Вентральная поверхность 

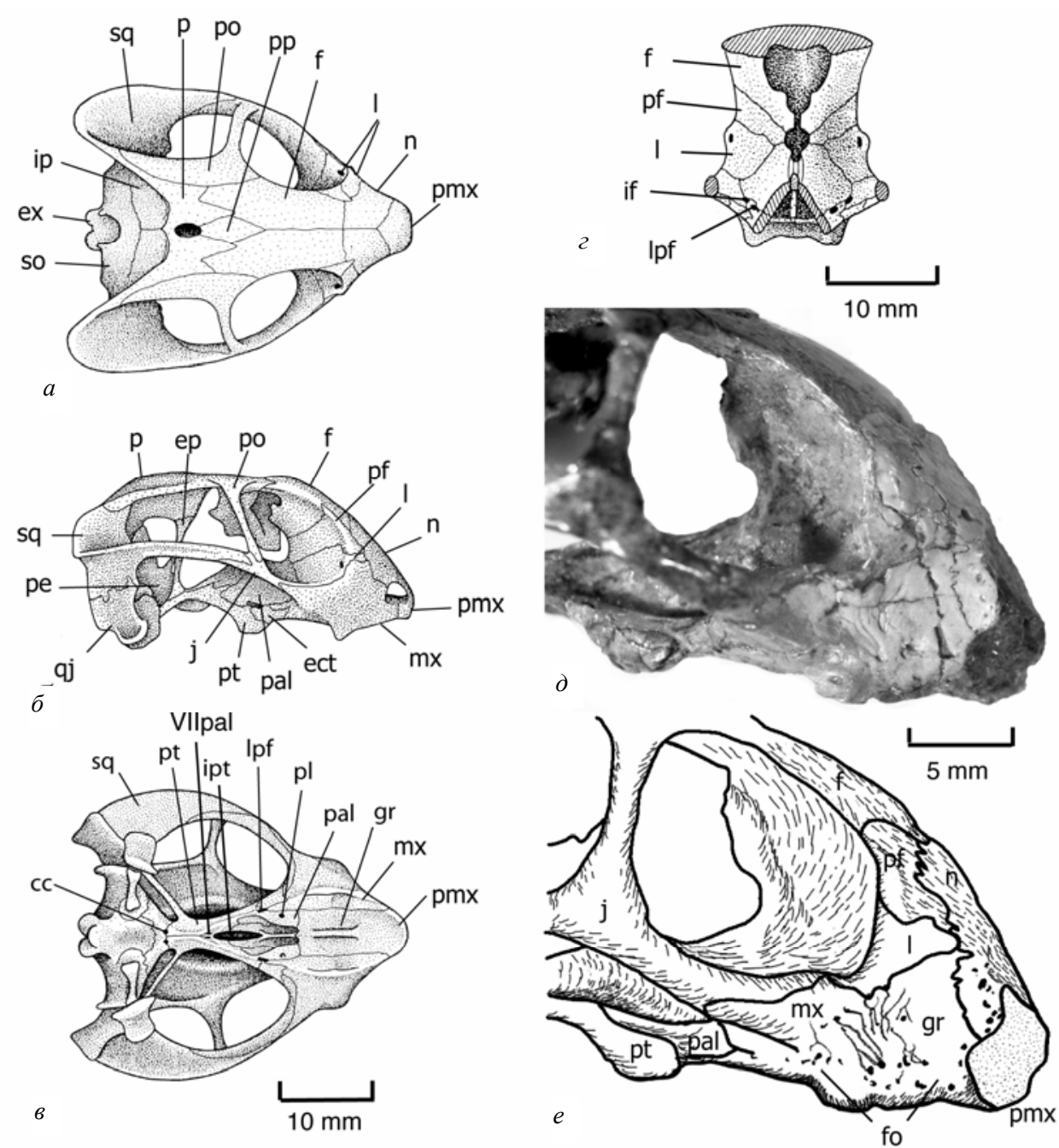

Рис. 1. Реконструкция черепа и передняя часть морды Myosaurus gracilis SAM PK 3526a: $a$ - вид снизу; $\sigma$ - вид сбоку; в - вид сверху; 2 - вид морды сзади; $\partial$ - фотография морды; $e-$ прорисовка инфраорбитальных отверстий и отпечатков кровеносных сосудов ( $a-2-$ слегка модифицировано по Клюверу [6]). Условные обозначения:ect - боковая крыловидная; $e p$ - верхнекрыловидная; $f$ - лобная; $f o$ - зона выхода инфраорбитальных каналов; $g r$ - желобки; $i p$ - межтеменная; $j$ - скуловая; $l$ - слезная; $m x$ - верхнечелюстная; $n$ - носовая; $p$ - теменная; $p a l$ - небная; $p m x$ - пречелюстная; $p o$ - заглазничная; $p p$ - предтеменная; $r f$ - предлобная; $p t$ - крыловидная; $q j$ - квадратно-скуловая; $s q$ - чешуйчатая; $c c$ - каротидные каналы; ipt - межптеригоидная впадина; if- инфраорбитальное отверстие; $p f$ - небное отверстие; $l p f$ - боковое небное отверстие; VII pal - отверстие для выхода небной ветви лицевого нерва

предчелюстной кости (рис. $1, a$ ) вогнута, отсутствуют парные гребни, осложняющие поверхность в передней части, вдоль срединного гребня тянутся два глубоких желобка (gr, см. рис. $1, a)$. Клыковой отросток на верхнечелюстной кости (рис. 1, б) маленький. Лабиальное отверстие отсутствует. Небные кости удлиненные, расширены кпереди, вентральная поверхность костей гладкая (см. рис. $1, a)$. Небное отверстие пронизывает небную кость в передней части (см. рис. $1, a$ ).
Боковое небное отверстие расположено на внешней стороне небной кости на уровне передних окончаний крыловидных костей (см. рис. $1, a$ ). Хоаны разделены длинной и узкой сошниковой костью (см. рис. $1, a$ ). Межптеригоидная впадина (см. рис. $1, a$ ) узкая, ее длина составляет $43 \%$ от длины хоан. Наружные крыловидные кости (см. рис. $1, a, \sigma)$ расширены кпереди, изолируя крыловидные кости от контакта с верхнечелюстными костями. 
Строение мозговой коробки и базикраниума в целом сходно с таковыми у Dicynodon [11], однако отличается отсутствием межтуберального гребня и передним расширением парабазисфеноидного отростка, который накрывает крыловидные кости вдоль задней трети межптеригоидной впадины. Характерной особенностью также является прохождение небной ветви VII нерва от передней стенки каротидных каналов до задней стенки межптеригоидной впадины (см. рис. $1, a)$ как у более поздних среднетриасовых форм.

Межвисочная область крыши черепа и теменные кости широкие (рис. 1, в). Предтеменная кость узкая, ланцетовидная (см. рис. 1,6 ). Заднелобные кости отсутствуют, теменное отверстие смещено кзади. Заглазничные кости протягиваются далеко назад, контактируя с чешуйчатыми костями (см. рис. $1, \sigma, в$ ). Межтеменная кость широкая, не участвует в строении задней части крыши черепа (см. рис. 1,8$)$. Чешуйчатые кости резко расширяются латерально над квадратными костями. Медиальные края правой и левой лобной и предлобной костей почти контактируют между собой (рис. 1, г).

Ростральные кости Myosaurus покрыты множеством небольших отверстий и ямок, окруженных отпечатками кровеносной сосудистой системы. Эти структуры представляют собой терминальные выходы инфраорбитальной артерии и нерва. Наиболее четко отпечатки сохранились на правой стороне образца SAM PK 3526а (рис 1, $\partial, e$ ), где можно определить две области усиленного кровоснабжения. Первая область приурочена к передним окончаниям носовых и частично верхнечелюстных костей в области ноздрей. Поверхность костей в этой области покрыта множеством мелких отверстий и ямок. Вторая область более обширна, она покрывает среднюю и заднюю части верхнечелюстных костей на уровне клыкового отростка и слезной кости. В этой области выделяются шесть крупных и около десяти мелких отверстий, от которых в антеро-вентральном и вентральном направлении протягиваются ветвящиеся бороздки. Наиболее крупные бороздки приурочены к задним инфраорбитальным отверстиям. Вход для инфраорбитальных сосудов и нервов в носовую капсулу
Myosaurus, вероятно, приурочен к отверстию между наружной крыловидной, скуловой и небной костями (см. рис. 1, 2).

Изучение поверхности костей морды в районе развития отпечатков кровеносных сосудов свидетельствует о том, что данные образования навряд ли могут быть связаны с роговым клювом, поскольку поверхность кости в этой области зеркально гладкая без каких-либо следов ругоз, характерных для клювообразного окончания морды у других таксонов дицинодонтов. На морде миозавра зона с ругозной поверхностью узкая и расположена значительно ниже - вдоль нижнего края верхнечелюстных костей, что свидетельствует об очень ограниченном дорсальном распространении рогового клюва. Таким образом, пространственная разобщенность зон развития ругоз и инфраорбитальных отверстий с наибольшей вероятностью свидетельствуют о локальном усилении кровоснабжением мягких тканей морды.

О специализации сосудов и нервов на поверхности морды также говорит и наличие двух отдельных отверстий: инфраорбитального, расположенного на границе скуловой, небной и внешней крыловидной костей, и максилярного, проходящего через боковое небное отверстие (см. рис. 1, г). Формирование отдельного нервно-сосудистого пучка, усиленно питающего участки мягких тканей на латеральной поверхности морды, вполне ожидаемое явление среди дицинодонтов, поскольку «недоразвитые» инфраорбитальные отверстия были обнаружены на латеральной поверхности верхнечелюстной кости Uraloannemeyeria (SGU D 104/1-2) и Dicynodon sp. (PIN, 4415/1).

\section{Обсуждение}

Особенности развития инфраорбитальных отверстий среди териодонтов детально обсуждались Л.П. Татариновым [5, 12], где автор отрицал возможность гомологизации данных отверстий с латеральными верхнечелюстными отверстиями диапсид. Принципиальное различие заключается в том, что у териодонтов формируется независимый нервно-сосудистый пучок и соответствующий ему инфраорбитальный канал, пронизывающий латерально верхнечелюстную кость, у диапсид же формирование латеральных 
максилярных отверстий связано с аферентными окончаниями альвеолярного нерва, проникающими на латеральную поверхность верхнечелюстной кости через множество обособленных и упорядоченных отверстий. Эти наблюдения позволяют говорить о том, что у дицинодонтид усиленная иннервация мягких тканей морды формировалась, так же как и у териодонтов, путем образования отдельного инфраорбитального нервно-сосудистого пучка.

В топологии расположения инфраорбитальных каналов териодонтов были установлены две основные схемы. Для тероцефалов (Moschowaitsia vjuschkovi) характерно усиление иннервации и кровоснабжения в дистальной области морды в районе носа (рис. 2, a), при этом отпечатки кровеносных сосудов на поверхности верхнечелюстной кости свидетельствуют о незначительной толщине мягких тканей на морде, для цинодонтов (Dvinia prima, Permocynodon suhkini), наоборот, характерно более заднее расположение инфраорбитальных каналов (рис. 2, б) и отсутствие отпечатков кровеносных сосудов $[5,12,13]$. Последнее трактуется как свидетельство наличия довольно толстых мягких тканей, что подтверждается также и наличием области прикрепления m. levator labii superior (mls, см. рис. 2, б). Приуроченность основных инфраорбитальных отверстий Myosaurus к задней части верхнечелюстной кости говорит о сходном с цинодонтами типе формирования зон усиленного кровоснабжения и иннервации, однако наличие хорошо развитых отпечатков кровеносных сосудов отражает незначительную толщину мягких тканей, покрывавших морду, что свидетельствует об отсутствии сколь-либо серьезно развитой губной/лицевой мускулатуры.
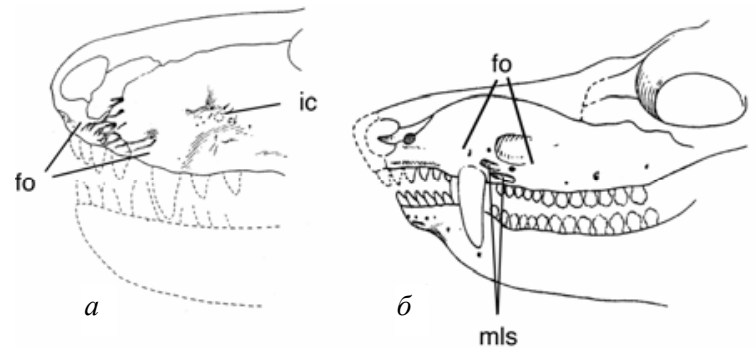

Рис. 2. Реконструкция инфраорбитальных каналов у плотоядных терапсид по Татаринову [5]. $a$-Moschowaitsia vjuschkovi; 6 - Permocynodon suhkini. Условные обозначения: $m l s$ - область прикрепления m.levator labii suprior
Аналогичное цинодонтам формирование инфраорбитальных отверстий и обширной сети кровеносных сосудов на морде Myosaurus позволяет предполагать развитие сенсорных осязательных зон, которые по аналогии с современными млекопитающими могли быть покрыты вибриссами или вибриссоподобными образованиями. Такое предположение очень хорошо соответствует гипотезе М. Клювера [6] о насекомоядности Myosaurus в отличии от остальных растительноядных дицинодонтов. В пользу этой гипотезы говорят и необычно широкие глазницы, которые на $30 \%$ больше сходного по размерам примитивного дицинодонта Emydops. Все эти факты позволяют отнести миозавра к мелким насекомоядным терапсидам, которые вели сумеречный образ жизни. Необычный для дицинодонтов образ жизни этого животного вполне укладывается в рамки послекризисной экосистемы, существовавшей на территории Южной Африки в начале раннего триаса. Во время позднепермского кризиса были разрушены устойчивые прибрежные экосистемы речных пойм, а речная динамика и переработка берегов резко усилились [14], что в конечном счете привело к формированию узких и неустойчивых прибрежных экотонов с крайне обедненной фауной терапсид. В процессе этих перестроек, вероятно, и произошла диетарная переориентация и специализация мелких дицинодонтов, смогших на короткое время занять нишу мелких насекомоядных процинозухид, из которой они до конца раннего триаса были вытеснены более продвинутыми терапсидами - мелкими тринаксодонами. Последние, помимо вибрисс, имели турбиналии, что свидетельствует о теплокровности [15] и соответственно большей активности в холодное время суток.

Появление осязательных зон на морде миозавра свидетельствует о том, что один из ключевых признаков млекопитающих - наличие вибрисс, появился конвергентно и почти одновременно во всех группах терапсид (рис.3) в позднепермское - раннетриасовое время. Однако появление и закрепление этого признака в филогенетических линиях происходило не всегда, поэтому его наличие не говорит о настоящей маммальности, кото 


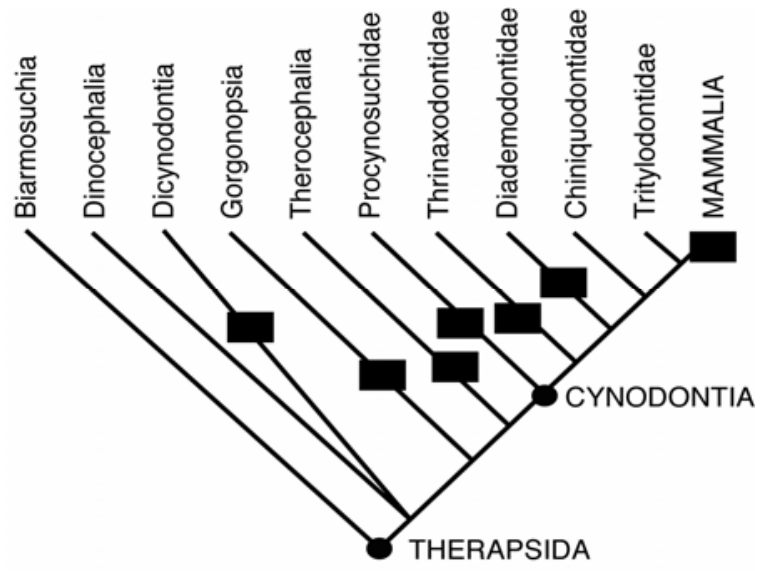

Рис. 3. Кладограмма зверообразных. Закрашенными прямоугольниками отмечены клады, в которых зарегистрировано развитие сенсорных зон и возможно вибрисс

рая сформировалась значительно позже в результате комбинации дополнительных «отработанных» ранее морфотипов.

Работа издана при поддержке РФФИ (грант 04-05-64635), Pal SIRP и Палеонтологической ассоччиации Великобритании.

\section{Библиографический список}

1. Broili F. Haare bei Reptilien // Anat. Anz. 1941. Bd.92. P.62-68.

2. Brink A.S. Speculation on some advanced mammalian characteristics in the higher mammal-like reptiles // Paleontologia Africana. 1957. №4. P.77-96.

3. Watson D.M.S. On the skeleton of a bauriamorph reptile // Proc. of the Zoology Society of London. 1931. P.35-98.

4. Valen L. van. Therapsids as mammals // Evolution. 1960. №14. P.304-313.
5. Татаринов Л.П. Развитие системы губных (вибриссовых) сосудов и нервов у териодонтов // Палеонтологический журнал. 1967. №1. С.3-17.

6. Cluver M.A. The cranial morphology of the Lower Triassic dicynodont Myosaurus gracilis // Annals of the South African Museum. 1974. №66. P.35-54.

7. Cosgriff J.W., Hammer R.H. New species of Dicynodontia from the Fremow Formation // Antarctic Journal of the United States. 1979. V.14, №5. P.30-32.

8. Haughton S.H. Investigations in South African fossil reptiles and Ampibia Pat 10 Descriptive catalogue of the Anomodontia, with especial reference to the examples in the South African Museum // Annals of the South African Museum. 1917. №12. P.127-174.

9. Angielczyk K.D. Preliminary phylogenetic analysis and stratigraphic congruence of the dicynodont anomodonts (Synapsida: Therapsida) // Palaeontologia Africana. 2001. №37. P.53-79.

10. King G.M. Anomodontia // Handbuch der Paläoherpetologie. Stuttgart, 1988. V.17. 175 p.

11. Surkov M.V., Benton M.J. The basicranium of dicynodonts (Synapsida) and its use in phylogenetic analysis // Palaeontology. 2004. V.47, №3. P.619-638.

12. Татаринов Л.П. О формировании признаков млекопитающих у териодонтов // Палеонтологический журнал. 1965. №1. C.3-12.

13. Татаринов Л.П. К анатомии головы тероцефалов (сосуды, нервы и железы Moshowaitsia) // Там же. 1964. №2. C. $72-84$.

14. Smith R.M.H. Changing fluvial environments across the Permian Triassic boundary in the Karroo basin, South Africa and possible causes of tetrapod extinction // Paleogeography, Palaeoclimatology, Palaeoecology. 1995. №117. P.81-104.

15. Hillenius W.J. Turbinates in therapsids - evidence for the Late Permian origin of mammalian endothermy // Evolution. 1994. №48. P.207-229. 